\title{
Moderate hypoxia but not warming conditions at larval stage induces adverse carry-over effects on hypoxia tolerance of European sea bass (Dicentrarchus labrax) juveniles
}

\author{
Cadiz Laura ${ }^{1}$, Ernande Bruno ${ }^{2}$, Quazuguel Patrick ${ }^{1}$, Servili Arianna ${ }^{1}$, Zambonino Jose-Luis ${ }^{1}$, \\ Mazurais David ${ }^{1, *}$
}

1 IFREMER, Centre de Bretagne, LEMAR (UMR 6539), 29280 Plouzané, France

${ }^{2}$ IFREMER, Centre Manche Mer du Nord, 62200 Boulogne-sur-Mer, France

*Corresponding author : David Mazurais, email address : david.mazurais@ifremer.fr

\begin{abstract}
:
Environmental conditions, to which organisms are exposed during all their life, may cause possible adaptive responses with consequences in their subsequent life-history trajectory. The objective of this study was to investigate whether ecologically relevant combinations of hypoxia $(40 \%$ and $100 \%$ air saturation) and temperature $\left(15^{\circ}\right.$ and $\left.20^{\circ} \mathrm{C}\right)$, occurring during the larval period of European sea bass larvae (Dicentrarchus labrax), could have long-lasting impacts on the physiology of resulting juveniles. Hypoxic challenge tests were performed over one year to give an integrative evaluation of physiological performance. We revealed that juvenile performance was negatively impacted by hypoxia but not by the thermal conditions experienced at larval stage. This impact was related to the prevalence of opercular abnormalities. The present study indicates that exposure to a moderate hypoxia event during larval stage may have adverse carry-over effects, which could compromise fitness and population recruitment success.
\end{abstract}

\section{Highlights}

- Sea bass juveniles exposed to moderate hypoxia at larval stage have lower tolerance to acute hypoxia. Juveniles with opercular deformities exhibits lower resistance time to acute hypoxia. Exposure to moderate hypoxia environment at larval stage induces opercular malformation. 
Keywords: Hypoxia, Temperature, Developmental plasticity, Carry-over effects, Opercular malformation, European sea bass

\section{Abbreviations}

- days post hatching, dph

- loss of equilibrium, LOE 


\section{Introduction}

Environmental conditions encountered by living organisms including fish during critical windows of early life stages can affect their development (Burggren and Reyna, 2011; Fokos et al., 2017; Jonsson and Jonsson, 2014; Lindström, 1999; Monaghan, 2008; Rödel and Monclús, 2011). A "critical window" for development can be defined as a period when an organism may experience a suite of morphological and physiological modifications in response to intrinsic or environmental factors (Burggren and Mueller, 2015; Burggren and Reyna, 2011). The ability of an organism to produce lasting phenotypes in reaction to an external environmental input is defined as developmental plasticity (Nettle and Bateson, 2015). Lasting modifications of traits resulting from developmental plasticity may be adaptive or not. Indeed, adverse environmental factors may disrupt development of individuals to produce non-adaptive outcomes affecting their fitness (Bateson et al., 2014; Lindström, 1999). In contrast, adaptive developmental plasticity define the ability of developing organisms to fine tune their phenotypes in response to the environmental conditions encountered, in order to produce animals able to better tolerate similar conditions at later life stages (Bateson et al., 2014; Nettle and Bateson, 2015).

Coastal marine areas are particularly prone to spatial and temporal fluctuations in terms of environmental conditions. These fluctuations are intensifying as a result of the multifaceted on-going global change, which is reflected by several episodes of variable magnitude combining warming and hypoxia (Díaz and Rosenberg, 2011; Levin and Breitburg, 2015). Marine coastal and estuarine ecosystems serve as nursery for a large number of fish species which are thus likely to be exposed to periods of low dissolved oxygen (DO) and high temperature at critical windows for development. According to that, fish larvae whose morpho- and organogenesis are not fully achieved may be particularly susceptible to the surrounding environment including oxygen $\left(\mathrm{O}_{2}\right)$ and temperature conditions.

Short term effects of temperature and hypoxia on fish performance have been intensively investigated at early life stages. Within a species thermal tolerance range, temperature controls growth rate following bell shaped curve (O'Connor et al., 2007). Beyond thermal tolerance limits of species, temperature may induce developmental abnormalities with potential sub-lethal or lethal consequences (Korwin Kossakowski, 2008; Perrichon et al., 2017; Pimentel et al., 2014; Politis et al., 2017). For its part, hypoxia exposure can result in hatch defects (e.g. lower hatch rates, delayed hatching), metabolic depression, cardiorespiratory physiological regulation and skeletal deformities which may compromise the growth and survival of early life fish (Bagatto, 2005; Hassell et al., 2008a,b; Mejri et al., 2012; Mendez-Sanchez and Burggren, 2017; Nicholson et al., 2008; 
Vanderplancke et al., 2015b; $\mathrm{Wu}, 2009$ ). Temperature and $\mathrm{O}_{2}$ conditions encountered during early life stages have also been shown to induce long term effect on fish performance. Temperature may have effects on developmental trajectories in fish including modification of growth, sex determination/differentiation, age at sexual maturity (Ali et al., 2003; Baroiller et al., 2009; Jonsson and Jonsson, 2014). In zebrafish (Danio rerio), larvae that survive an exposure to hypoxia can display reduced swimming capacity (18\% DO; Widmer et al., 2006) and altered avoidance reaction to aggression (10\% DO; Marks et al., 2005). Data obtained in zebrafish suggest also that early severe hypoxia ( $5 \%$ DO) exposure may increase the subsequent hypoxia tolerance at adult stage (Robertson et al., 2014). Such long term beneficial effects on hypoxia tolerance have only been shown in freshwater fish model species. In contrast, recent data obtained in Atlantic salmon (Salmo salar) indicated that fish exposed to mild hypoxia $(50 \%$ DO) during early life stages tends to exhibit lower hypoxia tolerance compared with those raised in normoxia (Wood et al., 2017). While fish with active locomotive ability may migrate to new suitable habitats to escape a harsh environment, this option may represent an impossible task in the case of extended hypoxic zones in the coastal area, especially for fish with reduced active swimming capacity particularly at early life stages. Therefore, understanding the long term effects of these environmental constraints on fish physiological performance is essential to better predict potential impacts on juvenile recruitment, particularly in temperate marine fish species. Indeed, temperate coastal areas mostly experience moderate environmental episodes, which may not induce immediate visible effects in terms of mortality.

European sea bass (Dicentrarchus labrax) larvae generally enter shallow coastal areas after the flexion stage and could therefore be exposed to environmental fluctuations, while their larval development is not totally completed (Dufour et al., 2009). Previous studies on European sea bass revealed that exposure to moderate hypoxia $(40 \% \mathrm{DO})$ at the larval stage could induce long lasting effects on metabolic parameters and on digestive and hemoglobin systems (Cadiz et al., 2017a; Cadiz et al., 2017b; Vanderplancke et al., 2015a; Zambonino-Infante et al., 2017). However, the global impact of early exposure to realistic environmental fluctuations, such as combined temperature and hypoxia, on the overall individual fitness of sea bass remains poorly understood. The present study investigates hypoxia tolerance in European sea bass juveniles that have been previously exposed to the combination of different oxygen ( $40 \%$ and $100 \%$ air saturation) and temperature $\left(15^{\circ} \mathrm{C}\right.$ and $\left.20^{\circ} \mathrm{C}\right)$ conditions from flexion stage until end of larval development (i.e. 43-50 days post hatching). These environmental conditions are realistic and may be found by European sea bass larvae at this developmental stage in Atlantic coastal and estuarine nursery (Bento et al., 2016; Dufour et al., 2009). Following the larval period, fish experienced a five-month period of common garden $\left(15-17^{\circ} \mathrm{C}\right.$, $100 \%$ air saturation). Then, fish tolerance to hypoxia challenge was investigated four times at regular 
time intervals over one year to evaluate the global physiological status of juveniles. Hypoxia challenge was used since the performance of fish to resist to hypoxia challenge depends on the ability of individuals to regulate physiological processes related to oxygen extraction and transport, cardiovascular functions and energy metabolism (Roze et al., 2013). The global morphological appearance of operculum, which contributes to water flow across the gills lamellae and allows $\mathrm{O}_{2}$ extraction, was also examined. The individuals' responses to the challenge tests were examined in relation to their early-life environment and to the presence of opercular deformities.

\section{Materials and methods}

\subsection{Animal rearing and treatments}

The present work was performed within IFREMER facilities in accordance with French and European policies and the guidelines of the French Animal Care Committee (Agreement number: APAFIS\#5173).

One day post hatching $(\mathrm{dph})$ larvae of $D$. labrax were purchased from a commercial hatchery (Aquastream, Ploemeur, France). D. labrax larvae were reared under normal oxygen conditions in 12 tanks at $15 \pm 0.4^{\circ} \mathrm{C}$ water temperature and $35 \pm 0.2 \%$ salinity at an initial density of 80 larvae/L (20 000 larvae/tank). They were fed daily with Artemia according to Zambonino et al. (1996) until the end of larval development. Artemia cysts were purchased from Catvis BV ('s-Hertogenbosch, The Netherlands). Hatching of Nauplii ( $\mathrm{Na}$ ) was obtained after $24 \mathrm{H}$ at $25^{\circ} \mathrm{C}$, and 1-day old Artemia (A1) were produced using (n-3) TOP RICH enrichment (Catvis BV, 's-Hertogenbosch, The Netherlands) following supplier's recommendations (300 ppm for $16-24 \mathrm{~h}, 25^{\circ} \mathrm{C}, 300-500 \mathrm{~A} / \mathrm{ml}$ ). The feeding schedule was as follows: days 8-15, 50-300 Na per larva*day1, then from 120 A1 per larva*day-1 for 16-day-old larvae up to 1000 A1 per larva*day -1 for 45-day-old larvae. Water temperature was progressively increased from $15^{\circ} \mathrm{C}$ to $20^{\circ} \mathrm{C}$ in six tanks between 23 and $28 \mathrm{dph}$ for acclimation purposes. From $28 \mathrm{dph}$ (flexion stage), three replicate tanks of larvae were exposed to each combination of temperature and oxygenation levels: i) $15^{\circ} \mathrm{C}\left[40 \%\right.$ air saturation $\left.\left(3.2 \mathrm{mg} \mathrm{O}_{2} \mathrm{~L}^{-1}\right)\right]$; ii) $15^{\circ} \mathrm{C}\left[100 \%\right.$ saturation $\left.\left(8.2 \mathrm{mg} \mathrm{O}_{2} \mathrm{~L}^{-1}\right)\right]$; iii) $20^{\circ} \mathrm{C}$ [40\% air saturation $\left.\left(2.95 \mathrm{mg} \mathrm{O}_{2} \mathrm{~L}^{-1}\right)\right]$ and iv) $20^{\circ} \mathrm{C}$ [100\% air saturation $\left(7.35 \mathrm{mg} \mathrm{O}_{2} \mathrm{~L}^{-1}\right)$ ]. Hypoxic conditions were created by bubbling $\mathrm{N}_{2}$ in a gas equilibration column placed upstream of the experimental tank. Dissolved $\mathrm{O}_{2}$ was monitored daily using an Odeon oxygen meter (ODEON Classic OPTOD; Caudan, France). Other water quality parameters $(\mathrm{pH}, 7.9 \pm 0.1$; salinity: $35 \pm 0.2 \%$ ) were also checked daily in each tank during the experiment. It had previously been determined that the level of hypoxia used did not induce 
mortality; thus, genetic selection during larval exposure was avoided. Larvae were returned to normal oxygen conditions ( $100 \%$ air saturation) at $43 \mathrm{dph}\left(745^{\circ} \mathrm{C} \cdot\right.$ day $)$, for larvae exposed at $20^{\circ} \mathrm{C}$, and at $50 \mathrm{dph}\left(750^{\circ} \mathrm{C}\right.$-day), for larvae exposed to $15^{\circ} \mathrm{C}$, to ensure that larval treatments were applied at the same stage of development. Replicate tanks were then pooled into one $1 \mathrm{~m}^{3}$-tank per treatment and kept under normoxic conditions at $15-17^{\circ} \mathrm{C}$. At this stage, the fish were fed with a commercial diet (NeoSupra; Coopérative Le Gouessant, Lamballe, Côtes-d'Armor, France). The quantity of feed distributed per day was not recorded. At $152 \mathrm{dph}, 100$ fish from each of the treatment tanks were selected and tagged subcutaneously to identify the early stage treatments (Passive Integrated Transponder; PIT-tag) for individual identification. The fish were then fed with NeoGrower commercial diet (Coopérative Le Gouessant; Lamballe, Côtes-d'Armor, France) and pooled in a 4- $m^{3}$ tank.

\subsection{Mass monitoring}

Larval mass was evaluated on 150 larvae per group (50 larvae from each replicate tank) at the beginning (22 dph) and at the end of the exposure (43/50 dph). Larvae were euthanized with an excess of anesthetic (Tricaine methane-sulfonate 100 mg L-1, Pharmaq; Hampshire, United Kingdom) and transferred to formaldehyde for fixation (4\%) until individual mass measurement. All the juveniles from each experimental group $(n \approx 80)$ were weighed at 549 dph after light anesthesia (Tricaine methane-sulfonate $10 \mathrm{mg} \mathrm{L}-1$ ).

\subsection{Hypoxia challenge}

Four standardized hypoxia challenge tests were conducted over one year (summer/autumn at $176 \mathrm{dph}$, winter at $296 \mathrm{dph}$, spring at $420 \mathrm{dph}$ and summer/autumn at $547 \mathrm{dph}$ ) on all fish from each treatment tanks according to the protocol described in Roze et al (2013). To avoid unnecessary stress and additional sources of variation, challenge tests were conducted in the fish rearing tank and $48 \mathrm{~h}$ prior to challenge, individuals were unfed. Water salinity did not change significantly over the duration of the experiment. Water temperature was intentionally not controlled and it therefore followed the natural seasonal cycle $\left(17^{\circ}\right.$ at $176 \mathrm{dph} ; 10^{\circ}$ at $296 \mathrm{dph} ; 13^{\circ} \mathrm{C}$ at $420 \mathrm{dph}$ and $17^{\circ}$ at 547 dph).

Hypoxia challenge consisted in a rapid decrease in water oxygenation (from nearly $100 \%$ to $20 \%$ air saturation in about $1 \mathrm{~h}$ ) followed by a much slower descent (approximately 2\% air saturation per hour) until the experiment ended. Ambient oxygenation was controlled by bubbling nitrogen in the input of a submersible pump placed in the tank. The water oxygen level was monitored using a 
calibrated Odeon oxygen meter. As individual fish lost their ability to maintain equilibrium, they were quickly removed from the experimental arena, identified (tag reading) and placed in a fully aerated recovery tank. The corresponding time (loss of equilibrium; LOE) and oxygen level (incipient lethal of oxygen saturation; ILOS) were also recorded. The hypoxia challenge ended when the last fish was recovered.

\subsection{Identification of opercular deformities}

Two weeks after the last hypoxia challenge test, juveniles from experimental groups were slightly anesthetized (Tricaine methane-sulfonate $20 \mathrm{mg} \mathrm{L}-1$ ). Then, individuals were examined macroscopically to identify unilateral and bilateral opercular deformities. Attention was paid to gillcover abnormalities without going in their deep characterization. Example of opercular deformity revealing gill-cover abnormality is illustrated in Fig.1.

\subsection{Data analysis and statistics}

The resistance of sea bass juveniles to hypoxia challenge was measured as the fraction of individuals without equilibrium loss as a function of time under hypoxic conditions using the KaplanMeier estimator of survival time (LOE), referred to as resistance time thereafter, being equivalent to time to death (Kaplan and Meier, 1958).

Firstly, the effects of early-life hypoxic and warming exposure on juvenile resistance to hypoxia challenge were examined by the modification of the log-rank test, which is a non-parametric test allowing to compare survival (here resistance) time distribution between samples (Peto and Peto, 1972). Tests were stratified according to dates to account for temporal variability in global resistance time distribution across the four hypoxia challenge tests. The effects of early-life temperature and oxygen level were tested both jointly (i.e. differences between cross-factorial treatments) and independently (i.e. differences between the two modalities of each factor separately). As the test consists in across sample comparison, interactions could not be tested.

Secondly, the effect of opercular deformities on juvenile tolerance to hypoxia challenge was estimated by parametric survival regression models where the hypoxia resistance time follows a parametric distribution. Various classical resistance time distributions were tested and the AIC (Akaike Information Criterion) was used to compare the performance of the corresponding models and choose one distribution. Models included opercular malformation as a factor (with three modalities corresponding to the number of opercules affected: no, unilateral or bilateral deformity) to test its effect on hypoxia resistance, date as a strata to account for temporal variability, and their 
interaction. Significance of the effects was tested by likelihood ratio tests between nested models respecting marginality of the effects (type II tests; (Fox and Weisberg, 2011). Post-hoc pairwise comparisons between opercular deformity modalities at each date were performed using simultaneous tests for general linear hypotheses in parametric models (Hothorn et al., 2008). Based on our AIC analysis, parametric model with a Weibull distribution was the most appropriate to describe the data. Hypotheses underlying Weibull survival regression models were checked (Fox and Weisberg, 2011).

Finally, the incidence of opercular malformation in relation to early-life hypoxic and warming exposure was assessed by multinomial regression models that allow modelling categorical variables with more than two modalities as response variables. More precisely, we used these models to analyse how the probability being undeformed, unilaterally or bilaterally deformed was influenced by early-life temperature as a continuous variable, early-life oxygen level as a categorical variable and their interaction. Significance of the effects was again tested by likelihood ratio type II tests.

Throughout analyses, differences were considered significant at the $95 \%$ confidence level (pvalue $<0.05$ ). All statistical analyses were performed using $R$ software ( $R$ Core Team 2016). Survival analyses were performed using the 'survival' package (Therneau and Grambsch, 2000; Therneau, 2015), post-hoc pairwise comparisons with the 'multcomp' package, Weibull survival regression diagnostics with the package 'SurvRegCensCov' (Hubeaux and Rufibach, 2015), and multinomial regressions with the package 'nnet' (Venables and Ripley, 2002). Mass data were log-transformed to fit a normal distribution and they were checked for normality (Shapiro test) and equality of variances (Levene test). Two-way ANOVAs were used to determine the effects of larval treatments (oxygen and temperature) on larval and juvenile body mass. Tukey's test $(p<0.05)$ was performed for post-hoc comparisons.

\section{Results}

\subsection{Effect of early-life hypoxic and warming exposure on larval and juvenile mass}

Whereas larval mass was similar among experimental groups at the beginning of the exposure period ( $\approx 1.8 \mathrm{mg}$, data not shown), it was significantly different at the end of the exposure period $\left(43 / 50 \mathrm{dph}\right.$ ) (table 1). The highest mass was observed for larvae reared at $20^{\circ} \mathrm{C}$ ( 2 times higher than at $15^{\circ} \mathrm{C} ; \mathrm{p}<1 * 10^{-6}$ ) and those reared in normoxia exhibited significantly higher mass than those exposed to hypoxia (1.3 times higher; $p<1 * 10^{-5}$ ). Sixteen months after the end of the exposure 
period (at $549 \mathrm{dph}$ ), juveniles previously exposed to $20^{\circ} \mathrm{C}$ still exhibited the highest mass ( 1.05 higher than $15^{\circ} \mathrm{C}$ Normoxia; $\left.\mathrm{p}=0.015\right)$. There was no significant difference in juveniles' mass related to previous exposure to hypoxia.

Table 1. Results of two-way ANOVA for effects of larval treatments (Temperature (Temp.) and Hypoxia (Hyp.)) on larval (22 and 43/50 dph) and juvenile (549 dph) body mass. Df means degrees of freedom. $n$ for each group 150 larvae and 100 juveniles. Standard deviation was indicated for each value. Significant differences between groups are identified with different letters (Tukey's test).

\begin{tabular}{|c|c|c|c|c|c|c|c|c|}
\hline & $\begin{array}{c}15^{\circ} \mathrm{C} \\
\text { Normoxia }\end{array}$ & $\begin{array}{c}15^{\circ} \mathrm{C} \\
\text { Hypoxia }\end{array}$ & $\begin{array}{c}20^{\circ} \mathrm{C} \\
\text { Normoxia }\end{array}$ & $\begin{array}{c}20^{\circ} \mathrm{C} \\
\text { Hypoxia }\end{array}$ & Df & Temp. & Нур. & $\begin{array}{c}\text { Temp. x } \\
\text { Hyp. }\end{array}$ \\
\hline $\begin{array}{c}22 \mathrm{dph} \\
(\mathrm{mg})\end{array}$ & $\begin{array}{r}1.74 \\
+0.29\end{array}$ & $\begin{array}{c}1.82 \\
+0.37\end{array}$ & 1.77 & & 1 & & & \\
\hline $\begin{array}{l}\text { 43/50 dph } \\
\text { (mg) }\end{array}$ & $\begin{array}{c}17.57 \\
\pm 0,25 b\end{array}$ & $\begin{array}{c}13.86 \\
\pm 0.89 a\end{array}$ & $\begin{array}{c}35.51 \\
\pm 1.43 d\end{array}$ & $\begin{array}{r}31.95 \\
\pm 1.83 \mathrm{c}\end{array}$ & 1 & $\begin{array}{l}\mathrm{F}=514.68 \\
\mathrm{p}<1 * 10^{-6}\end{array}$ & $\begin{array}{l}F=75.46 \\
p<1 * 10^{-5}\end{array}$ & $\begin{array}{l}F=0.55 \\
p=0.48\end{array}$ \\
\hline $\begin{array}{c}549 \mathrm{dph} \\
\text { (g) }\end{array}$ & $\begin{array}{c}143.6 \\
\pm 29.36 a\end{array}$ & $\begin{array}{c}143.9 \\
\pm 36.7 a\end{array}$ & $\begin{array}{c}148.5 \\
\pm 40.12 b\end{array}$ & $\begin{array}{c}151.7 \\
\pm 34.73 b\end{array}$ & 1 & $\begin{array}{c}F=9.4 \\
p=0.015\end{array}$ & $\begin{array}{c}F=0.7 \\
p=0.43\end{array}$ & $\begin{array}{l}F=0.5 \\
p=0.51\end{array}$ \\
\hline
\end{tabular}

\subsection{Effect of early-life hypoxic and warming exposure on juvenile tolerance to hypoxia challenge} test

Despite the variability of the response over the four challenge tests, juveniles that experienced early-life hypoxia event showed lower resistance to hypoxia than individuals from the control group (log-rank test: $p=1.5^{*} 10^{-5}$, Fig.2). In contrast, the four challenge tests did not reveal any effect of temperature on the ability of fish to tolerate hypoxia; $p=0.07$ (Fig.3).

\subsection{Effect of opercular deformities on juvenile tolerance to hypoxia challenge test}

Macroscopic analysis of opercular regions revealed gill-cover abnormality. Juveniles with opercular deformities exhibited a significant decrease in resistance time to hypoxia challenge test compared to undeformed fish (significant opercular deformity effect; Fig.4) but this effect varied according to the date considered (significant interaction between opercular deformity and date, Fig.4). However, post-hoc pairwise comparisons between opercular deformity modalities (no vs unilateral, no vs bilateral, and unilateral vs bilateral deformity) at each date were all significant and 


\begin{tabular}{lccccc}
\hline unilateral & bilateral & $\begin{array}{c}\text { undeformed } \\
\text { vs. unilateral }\end{array}$ & $\begin{array}{c}\text { undeformed vs. } \\
\text { bilateral }\end{array}$ & $\begin{array}{c}\text { unilateral } \\
\text { vs. } \\
\text { bilateral }\end{array}$ \\
\hline $176 \mathrm{dph}$ & $21 \%$ & $39 \%$ & $\mathrm{p}<1 * 10^{-4}$ & $\mathrm{p}<1 * 10^{-4}$ & $\mathrm{p}<1 * 10^{-4}$ \\
$296 \mathrm{dph}$ & $19 \%$ & $43 \%$ & $\mathrm{p}<1 * 10^{-4}$ & $\mathrm{p}<1 * 10^{-4}$ & $\mathrm{p}<1 * 10^{-4}$ \\
$420 \mathrm{dph}$ & $18 \%$ & $34 \%$ & $\mathrm{p}<1 * 10^{-4}$ & $\mathrm{p}<1 * 10^{-4}$ & $\mathrm{p}<1 * 10^{-4}$ \\
$549 \mathrm{dph}$ & $30 \%$ & $56 \%$ & $\mathrm{p}<1 * 10^{-4}$ & $\mathrm{p}<1 * 10^{-4}$ & $\mathrm{p}=0.04$ \\
\hline
\end{tabular}

showed that deformity always reduces resistance time, and that resistance time is lowest when fish exhibit bilateral deformities (table 2; Fig. 4). More precisely, fish with unilateral opercular deformities exhibited a decrease in resistance time compared to undeformed fish ranging from $18 \%$ to $30 \%$ depending on dates (table 2) while those with bilateral opercular deformities has a resistance time decreased by $34 \%$ to $56 \%$ according to the date.

Table 2. Effects of opercular deformities upon resistance time to the hypoxia challenge test at the different dates. Data are given in percentage of resistance time relative to undeformed individuals (columns unilateral and bilateral). Post-hoc pairwise comparisons of resistance time between no, unilateral and bilateral opercular deformities were evaluated using simultaneous tests for general linear hypotheses in parametric models.

\section{3}

3.4 Effect of early-life hypoxic and warming exposure on the presence of opercular malformations

The percentages of juveniles exhibiting opercular malformations in each experimental group are indicated in table 3. According to the multinomial regression model on opercular deformities, 256 hypoxia exposure at the larval stage strongly increased the risk of developing an opercular deformity 257 at juvenile stage (Chisq $\left.=69, \mathrm{df}=2, \mathrm{p}=1.2 * 10^{-15}\right)$. The relative risk of a unilateral and a bilateral 258 opercular malformation was 4 or 5 times higher, respectively, when juveniles experienced an early259 life hypoxia event ( $8.68 \%$ and $1.35 \%$ of the total population) compared to those reared in normoxia 260 (2.17\% and $0.31 \%$ of the total population). Early temperature condition also significantly influenced 261 the prevalence of opercular malformation (Chisq $=13, d f=2, p=0.0017$ ). However, the effect was 
inconsistent between unilateral and bilateral opercular malformation: while the relative risk of unilateral malformations at $20^{\circ} \mathrm{C}$ was 1.2 fold higher than at $15^{\circ} \mathrm{C}$, it was 5 fold lower for the relative risk of bilateral malformations.

Table 3. percentages of juveniles with gill cover abnormalities (unilateral or bilateral) for each experimental group ( $\mathrm{N}$ : normoxia; $\mathrm{H}$ : Hypoxia)

\begin{tabular}{cccccccccc}
\hline & $15^{\circ} \mathrm{CN}$ & $15^{\circ} \mathrm{CH}$ & $20^{\circ} \mathrm{CN}$ & $20^{\circ} \mathrm{CH}$ & Total H & Total N & $\begin{array}{c}\text { Total } \\
15^{\circ} \mathrm{C}\end{array}$ & $\begin{array}{c}\text { Total } \\
20^{\circ} \mathrm{C}\end{array}$ & Total \\
\hline Unilateral & $1.24 \%$ & $3.73 \%$ & $0.93 \%$ & $4.95 \%$ & $8.68 \%$ & $2.17 \%$ & $4.97 \%$ & $5.88 \%$ & $10.85 \%$ \\
Bilateral & $0.31 \%$ & $1.24 \%$ & 0 & $0,31 \%$ & $1.35 \%$ & $0.31 \%$ & $1.35 \%$ & $0.31 \%$ & $1.86 \%$ \\
Total & $1.55 \%$ & $5.17 \%$ & $0.93 \%$ & $5.26 \%$ & $10.03 \%$ & $2.5 \%$ & $6.32 \%$ & $6.19 \%$ & $12.71 \%$ \\
\hline
\end{tabular}

\section{Discussion}

European sea bass larvae are likely to be exposed to environmental fluctuations when they enter shallow coastal and estuarine waters just after the flexion stage. In this context, the present study evaluated whether thermic and oxygen conditions encountered during sea bass larval development could have long-lasting impacts on physiological performance, particularly related to hypoxia tolerance. Present data reveal compensatory growth following larval exposure to moderate hypoxia and lower temperature. This result is in good agreement with known phase of accelerated gowth when favourable conditions are restored after a period of growth depression in fish (Ali et al., 2003). Moreover, our data revealed that early exposure to moderate hypoxia from day 28 to day $45 / 50$ post hatching had a negative effect on the subsequent capacity of fish to tolerate a hypoxic constraint. This effect is explained by an increase in the prevalence of opercular malformation. Even if early exposure to moderate hypoxia did not induce any significant mortality, we hypothesized that it produces adverse carry-over effects which are likely to affect fish fitness.

Our data revealed that European sea bass juveniles previously exposed to chronic moderate hypoxic water showed lower tolerance compared to control fish. This long term impact was globally observed throughout the four hypoxia challenges regularly performed for one year at juvenile stage despite the variability of response observed among dates. This variability is likely due to variations of 
factors related to hypoxia challenge procedure (water temperature, repeatability of the procedure) and phenotypic shuffling among tests (Killen et al., 2016). Early-life exposure to low dissolved oxygen at larval stage has modified developmental trajectories of European sea bass producing phenotypes that were not able to cope with hypoxia. Adaptive plasticity may prime an organism exposed to environmental constraints during early life stage to develop phenotypes that will allow coping better with similar situations later in life (Nettle and Bateson, 2015); Sheriff and Love, 2013). In contrast, early exposure to constraint may also have detrimental effects on developmental process with lifelong morphological or physiological impairment and, ultimately, negative impact on fitness (Hassell et al., 2008b; Lupien et al., 2009). Our results indicating negative effect of early exposure to hypoxia on subsequent hypoxia tolerance are consistent with recent data obtained in Atlantic salmon, Salmo salar, exposed to mild hypoxia (50\% DO) during early life stages (Wood et al., 2017) but contrasts with the adaptive developmental plasticity revealed in zebrafish adults that benefited from exposure to low dissolved oxygen (5\% DO) at embryonic stage (Robertson et al., 2014). Responses to early-life exposure to hypoxia appear likely to be highly species-specific and may also depend on the developmental window and on the intensity and duration of the early hypoxic constraint.

The mechanisms underlying long lasting responses to early hypoxia exposure are largely unknown in fish. In zebrafish, adaptive developmental plasticity of hypoxia tolerance resulted in a modification of the sex ratio in favor of males which exhibit a lower critical oxygen tension and higher hypoxia tolerance compared to females (Robertson et al., 2014). In the present study, hypoxia tolerance test was performed on European sea bass juveniles that did not exhibit any secondary sexual characters. In this species, sex differentiation takes place from 7 months old but testicular and ovarian maturation start from 2 and 3 years old, respectively (Piferrer et al., 2005). Therefore, the potential link between early-life exposure of European sea bass larvae to hypoxia and the sex determination/differentiation processes and its potential consequence with later lower hypoxia tolerance cannot be evaluated. During the exposure window, European sea bass larvae exhibit many morphological and physiological developments (e.a. ossification of bone structures, muscular development) (Darias et al., 2008; Koumoundouros et al., 2001). Thus, the adverse carry over effects observed on hypoxia tolerance was expected to be due to disruption of a developmental process. Hypoxia tolerance depends partly at least upon the capacity of fish to acquire oxygen from its environment (Mandic et al., 2009). According to that, our data provide evidence that hypoxia tolerance was particularly low in juvenile fish exhibiting apparent opercular malformation. In particular, we demonstrated that the highest the opercular malformation (bilateral > unilateral), the lowest tolerance to hypoxia. It is admitted that opercular malformation can negatively affect 
biological performance of fish and reduce their resistance to oxygen drops (Koumoundouros et al., 1997). In the present work, deformities consist in gill-cover abnormality which anatomically is attributed to the inside folding of operculum and suboperculum (gill cover elements), and a simultaneous curvature of the branchiostegal rays, corresponding to types I and III defined by Beraldo et al., 2003. Such deformities likely impair the pump function of opercular cavity and water flux across gills lamellae resulting in lower oxygen extraction capacities. Interestingly, our data revealed that prevalence of opercular malformation was significantly higher in juveniles previously exposed to moderate hypoxia. This effect, which concerned $10 \%$ of the population, explained the lower hypoxia tolerance observed in juveniles previously exposed to hypoxia. Indeed, no more significant impact of early hypoxia exposure on hypoxia tolerance was observed when considering juveniles without apparent opercular malformation. That means that compensatory growth, revealed for juveniles that were exposed to hypoxia and/or $15^{\circ} \mathrm{C}$ at larval stage, did not influence hypoxia tolerance.

Molecular and cellular processes underlying hypoxia-induced opercular deformities during sea bass larvae development still need to be deciphered. However, a possible alteration of the ossification process in the operculum induced by hyperventilation during hypoxia exposure can be hypothesized. The ossification of gill-cover elements is continuous, especially during fish larval stage. Previous work performed on the gilthead sea bream (Sparus aurata) suggested that an increase in ventilation frequency during larval development (i.e. $400^{\circ} \mathrm{C}$.days) resulted in gill-cover deformities (Beraldo et al., 2003). The hypothesis is reinforced by the fact that process of ossification continues in the bone structures of the gill-cover at around $500^{\circ} \mathrm{C}$.day in European sea bass, the period in which larvae were exposed to hypoxia in the present study (Darias et al., 2010).

Our results also showed an impact of warmer temperature at larval stage on the incidence of opercular deformities in sea bass juveniles. This effect depends on the number of deformities considered. While we could hypothesize that the increase of unilateral deformity prevalence may likely be explained by an increase in the ventilation frequency due to the higher metabolism resulting from warmer temperatures, the decrease of bilateral deformities with warmer temperature remains difficult to explain. However, this last result must be considered with caution as only 6 individuals out of 325 exhibited bilateral opercular deformities and more confidence can be put in the result on unilateral deformities.

In conclusion, we assume that exposure to moderate hypoxia and to a lesser extent to warm temperature in European sea bass larvae impact the fitness of part of the future juveniles. Indeed, it has to be pointed out that, in addition to the adverse effect on hypoxia tolerance, opercular 
deformities may also predispose gills to pathological infections, which could induce delay in growth and high mortality rates in fish juveniles as a consequence of parasite infestation (Abdel et al., 2004). Impact on opercular formation associated to decrease in hypoxia tolerance confirms that developmental, morphological and physiological responses to the early-life environment do not always allow a beneficial adaptive tuning of physiological functions, which should produce animals best suited for the environment they are likely to find later as juveniles or adults. Nevertheless, we cannot exclude other potential effects of early oxygen and temperature conditions on key physiological function (e.g. reproduction) not investigated in the present study. Physiological trade off associated with compensatory growth could particularly be addressed. Future research will help to better characterize the long term impact of early hypoxic and thermal conditions on components of fitness which could influence population recruitment success.

Acknowledgments. The first author was supported by a joint Ifremer-Région Bretagne doctoral grant and by the "Laboratoire d'Excellence" LabexMER (ANR-10-LABX-19).

\section{References}

Abdel, I., Abellan, E., Lopez-Albors, O., Valdes, P., Nortes, M. J. and Garcia-Alcazar, A. (2004). Abnormalities in the juvenile stage of sea bass (Dicentrarchus labrax L.) reared at different temperatures: types, prevalence and effect on growth. Aquaculture International 12, 523-538.

Ali, M., Nicieza, A. and Wootton, R. J. (2003). Compensatory growth in fishes: A response to growth depression. Fish and Fisheries 4, 147-190.

Bagatto, B. (2005). Ontogeny of cardiovascular control in zebrafish (Danio rerio): effects of developmental environment. Comparative biochemistry and physiology. Part A, Molecular \& integrative physiology 141, 391-400.

Baroiller, J. F., D'Cotta, H. and Saillant, E. (2009). Environmental effects on fish sex determination and differentiation. Sexual Development 3, 118-135.

Bateson, P., Gluckman, P. and Hanson, M. (2014). The biology of developmental plasticity and the Predictive Adaptive Response hypothesis. The Journal of physiology 592, 2357-2368. 
Bento, E. G., Grilo, T. F., Nyitrai, D., Dolbeth, M., Pardal, M. Â. and Martinho, F. (2016). Climate influence on juvenile European sea bass (Dicentrarchus labrax, L.) populations in an estuarine nursery: A decadal overview. Marine environmental research 122, 93-104.

Beraldo, P., Pinosa, M., Tibaldi, E. and Canavese, B. (2003). Abnormalities of the operculum in gilthead sea bream (Sparus aurata): Morphological description. Aquaculture 220, 89-99.

Burggren, W. W. and Reyna, K. S. (2011). Developmental trajectories, critical windows and phenotypic alteration during cardio-respiratory development. Respiratory physiology and neurobiology 178, 13-21.

Burggren, W. W. and Mueller, C. A. (2015). Developmental critical windows and sensitive periods as three-dimensional constructs in time and space. Physiological and Biochemical Zoology, 88, 91102.

Cadiz, L., Servili, A., Quazuguel, P., Madec, L., Zambonino-Infante, J.-L. and Mazurais, D. (2017a). Early exposure to chronic hypoxia induces short- and long-term regulation of hemoglobin gene expression in European sea bass ( Dicentrarchus labrax). The Journal of Experimental Biology 220, 3119-3126.

Cadiz, L., Zambonino-Infante, J.-L., Quazuguel, P., Madec, L., Le Delliou, H. and Mazurais, D. (2017b). Metabolic response to hypoxia in European sea bass ( Dicentrarchus labrax ) displays developmental plasticity. Comparative Biochemistry and Physiology Part B: Biochemistry and Molecular Biology 215, 1-9.

Darias, M. J., Zambonino-Infante, J. L., Hugot, K., Cahu, C. L., and Mazurais, D. (2008). Gene expression patterns during the larval development of European sea bass (Dicentrarchus labrax) by microarray analysis. Marine Biotechnology 10, 416-428.

Darias, M. J., Lan Chow Wing, O., Cahu, C., Zambonino-Infante, J. L. and Mazurais, D. (2010). Double staining protocol for developing European sea bass (Dicentrarchus labrax) larvae. Journal of Applied Ichthyology 26, 280-285.

Díaz, R. J. and Rosenberg, R. (2011). Introduction to Environmental and Economic Consequences of Hypoxia. International Journal of Water Resources Development 27, 71-82.

Dufour, V., Cantou, M. and Lecomte, F. (2009). Identification of sea bass (Dicentrarchus labrax) nursery areas in the north-western Mediterranean Sea. Journal of the Marine Biological Association of the United Kingdom 89, 1367-1374. 
Fokos, S., Pavlidis, M., Yiotis, T., Tsalafouta, A., Papandroulakis, N. and Dermon, C. R. (2017). Early life low intensity stress experience modifies acute stress effects on juvenile brain cell proliferation of European sea bass (D. Labrax). Behavioural brain research, 317, 109-121.

Fox, J. and Weisberg, S. (2011). Multivariate Linear Models in R. An R Companion to Applied Regression 1-31.

Hassell, K. L., Coutin, P. C. and Nugegoda, D. (2008a). Hypoxia impairs embryo development and survival in black bream (Acanthopagrus butcheri). Marine Pollution Bulletin 57, 302-306.

Hassell, K. L., Coutin, P. C. and Nugegoda, D. (2008b). Hypoxia, low salinity and lowered temperature reduce embryo survival and hatch rates in black bream Acanthopagrus butcheri (Munro, 1949). Journal of Fish Biology 72, 1623-1636.

Hubeaux, S. and Rufibach, K. (2015). SurvRegCensCov: Weibull Regression for a Right-Censored Endpoint with Interval-Censored Covariate. $\mathrm{R}$ package version 1.4. https://CRAN.Rproject.org/package=SurvRegCensCov

Hothorn, T., Bretz, F. and Westfall, P. (2008). Simultaneous inference in general parametric models. Biometrical Journal 50, 346-363.

Jonsson, B. and Jonsson, N. (2014). Early environment influences later performance in fishes. Journal of Fish Biology 85, 151-188.

Kaplan and Meier (1958). Nonparametric estimation from incomplete observations. Journal of the American Statistical Association. Journal of the American Statistical Association 53, 457-81.

Killen, S., Adriaenssens, B., Marras, S., Claireaux, G. and Cooke, S. J. (2016). Context dependency of trait repeatability and its relevance for management and conservation of fish populations Themed Issue Article : Conservation Physiology of Marine Fishes Context dependency of trait repeatability and its relevance for management and. Conservation Physiology 4, 1-19.

Korwin-Kossakowski, M. (2008). the Influence of Temperature During the Embryonic Period on Larval Growth and Development in Carp, Cyprinus Carpio L., and Grass Carp, Ctenopharyngodon Idella (Val.): Theoretical and Practical Aspects. Fisheries (Bethesda) 16, 231-314.

Koumoundouros, G., Oran, G., Divanach, P., Stefanakis, S. and Kentouri, M. (1997). The opercular complex deformity in intensive gilthead sea bream (Sparus aurata L.) larviculture. Aquaculture 156: 165-1, 165-177. 
Koumoundouros, G., Divanach, P., Anezaki, L., and Kentouri, M. (2001). Temperature-induced ontogenetic plasticity in sea bass (Dicentrarchus labrax). Marine Biology 139, 817-830.

Levin, L. A. and Breitburg, D. L. (2015). Linking coasts and seas to address ocean deoxygenation. Nature Climate Change 5, 401-403.

Lindström, J. (1999). Early development and fitness in birds and mammals. Trends in Ecology and Evolution 14, 343-348.

Lupien, S. J., McEwen, B. S., Gunnar, M. R. and Heim, C. (2009). Effects of stress throughout the lifespan on the brain, behaviour and cognition. Nature Reviews Neuroscience 10, 434-445.

Mandic, M., Todgham, A. E. and Richards, J. G. (2009). Mechanisms and evolution of hypoxia tolerance in fish. Proceedings. Biological sciences / The Royal Society 276, 735-44.

Marks, C., West, T. N., Bagatto, B. and Moore, F. B.-G. (2005). Developmental Environment Alters Conditional Aggression in Zebrafish. Copeia 2005, 901-908.

Mejri, S., Tremblay, R., Lambert, Y. and Audet, C. (2012). Influence of different levels of dissolved oxygen on the success of Greenland halibut (Reinhardtius hippoglossoides) egg hatching and embryonic development. Marine Biology 159, 1693-1701.

Mendez-Sanchez, J. F. and Burggren, W. W. (2017). Cardiorespiratory physiological phenotypic plasticity in developing air-breathing anabantid fishes (Betta splendens and Trichopodus trichopterus). Physiological reports 5, e13359.

Monaghan, P. (2008). Early growth conditions, phenotypic development and environmental change. Philosophical Transactions of the Royal Society B: Biological Sciences 363, 1635-1645.

Nettle, D. and Bateson, M. (2015). Adaptive developmental plasticity: what is it, how can we recognize it and when can it evolve?. Proceedings of the Royal Society B: Biological Sciences 282, 20151005.

Nicholson, G., Jenkins, G. P., Sherwood, J. and Longmore, A. (2008). Physical environmental conditions, spawning and early-life stages of an estuarine fish: Climate change implications for recruitment in intermittently open estuaries. Marine and Freshwater Research 59, 735-749.

O'Connor, M. I., Bruno, J. F., Gaines, S. D., Halpern, B. S., Lester, S. E., Kinlan, B. P. and Weiss, J. M. (2007). Temperature control of larval dispersal and the implications for marine ecology, evolution, and conservation. Proceedings of the National Academy of Sciences of the United 
471

472

Perrichon, P., Pasparakis, C., Mager, E. M., Stieglitz, J. D., Benetti, D. D., Grosell, M. and Burggren, W. W. (2017). Morphology and cardiac physiology are differentially affected by temperature in developing larvae of the marine fish mahi-mahi (Coryphaena hippurus). Biology open 6, 800809.

Peto and Peto (1972). Statistics in Town Planning Author ( s ): B . Benjamin Source : Journal of the Royal Statistical Society. Series A ( General ), Vol . 132 , No . 1 ( 1969 ), Published by : Wiley for the Royal Statistical Society Stable URL : http://www.jstor.org/stable/2. Journal of the Royal Statistical Society 132, 185-207.

Piferrer, F., Blázquez, M., Navarro, L., and González, A. (2005). Genetic, endocrine, and environmental components of sex determination and differentiation in the European sea bass (Dicentrarchus labrax L.). General and comparative endocrinology 142, 102-110.

Pimentel, M. S., Faleiro, F., Dionísio, G., Repolho, T., Pousão-Ferreira, P., Machado, J., and Rosa, R. (2014). Defective skeletogenesis and oversized otoliths in fish early stages in a changing ocean. Journal of Experimental Biology 217, 2062-2070.

Politis, S. N., Mazurais, D., Servili, A., Zambonino-Infante, J. L., Miest, J. J., Sørensen, S. R., and Butts, I. A. (2017). Temperature effects on gene expression and morphological development of European eel, Anguilla anguilla larvae. PloS one 12, e0182726.

Richards, J. G., Farell, A. P. and Brauner, C. J. (2009). Hypoxia in fish. 27, 528.

Robertson, C. E., Wright, P. A., Köblitz, L., Bernier, N. J., B, P. R. S. and Ko, L. (2014). Hypoxiainducible factor-1 mediates adaptive developmental plasticity of hypoxia tolerance in zebrafish , Danio rerio. Proceeding of the royal society $B \mathbf{2 8 1}$.

Rödel, H. G. and Monclús, R. (2011). Long-term consequences of early development on personality traits: A study in European rabbits. Behavioral Ecology 22, 1123-1130.

Roze, T., Christen, F., Amerand, A. and Claireaux, G. (2013). Trade-off between thermal sensitivity, hypoxia tolerance and growth in fish. Journal of Thermal Biology 38, 98-106.

Sheriff, M. J. and Love, O. P. (2013). Determining the adaptive potential of maternal stress. Ecology Letters 16, 271-280.

Therneau,T.M. and Grambsch, P.M (2000). Modeling Survival Data: Extending the Cox Model. 
Springer, New York. ISBN 0-387-98784-3.

500

501

502

503

504

505

506

507

508

509

510

511

512

513

514

515

516

517

518

519

520

521

522

523

Therneau, T.M. (2015). A Package for Survival Analysis in S. version 2.38, https://CRAN.Rproject.org/package=survival.

Vanderplancke, G., Claireaux, G., Quazuguel, P., Madec, L., Ferraresso, S., Sévère, A., Luis, J., Infante, Z. and Mazurais, D. (2015a). Hypoxic episode during the larval period has long - term effects on European sea bass juveniles (Dicentrarchus labrax ). 162, 367-376.

Vanderplancke, G., Claireaux, G., Quazuguel, P., Huelvan, C., Corporeau, C., Mazurais, D. and Zambonino-Infante, J.-L. (2015b). Exposure to chronic moderate hypoxia impacts physiological and developmental traits of European sea bass (Dicentrarchus labrax) larvae. Fish physiology and biochemistry 41, 233-242.

Venables, W. N. and Ripley, B. D. (2002). Statistics Complements to Modern applied statistics with S.

Widmer, S., Moore, F. B. G. and Bagatto, B. (2006). The effects of chronic developmental hypoxia on swimming performance in zebrafish. Journal of Fish Biology 69, 1885-1891.

Wood, A. T., Clark, T. D., Andrewartha, S. J., Elliott, N. G. and Frappell, P. B. (2017). Developmental Hypoxia Has Negligible Effects on Long-Term Hypoxia Tolerance and Aerobic Metabolism of Atlantic Salmon ( Salmo salar ). Physiological and Biochemical Zoology 90, 494-501.

Wu, R. S. S. (2009). Effects of Hypoxia on Fish Reproduction and Development. 1st ed. Elsevier Inc.

Zambonino, J. L., Calm, C. L., Peres, A., Quazuguel, P. and Le Gall, M. M. (1996). Sea bass ( Dicentrarchus labrax ) larvae fed different Artemia rations: growth, pancreas enzymatic response and development of digestive functions. Aquaculture 139, 129-138.

Zambonino-Infante, J. L., Mazurais, D., Servili, A., Cahu, C., Vanderplancke, G., Le Bayon, N., Huelvan, C. and Claireaux, G. (2017). An early-life hypoxia event has a long-term impact on protein digestion and growth in European sea bass juvenile. The Journal of Experimental Biology 220, 1846-1851. 


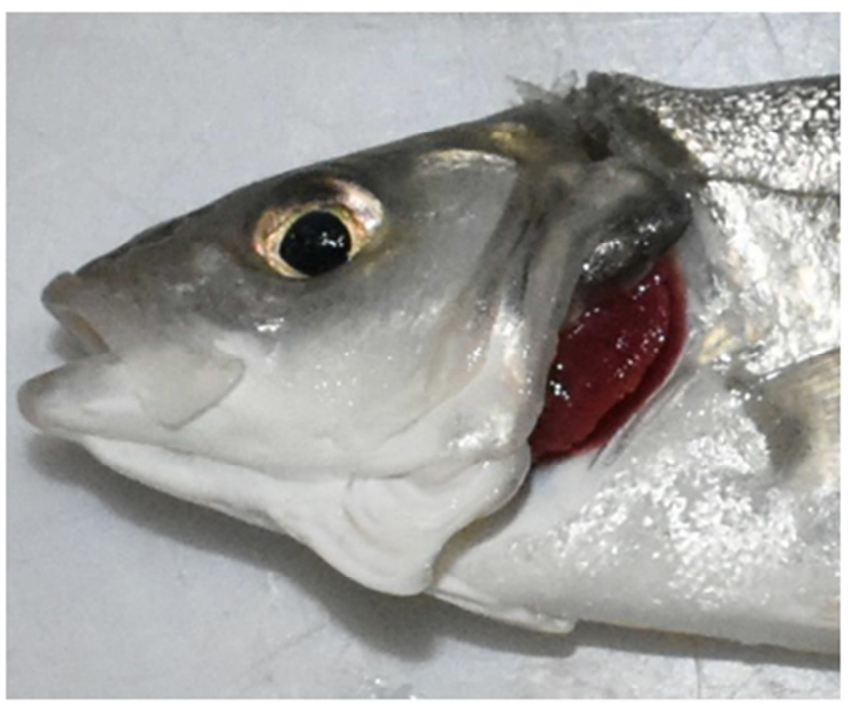

Figure 1: example of gill-cover abnormality observed in Juvenile 


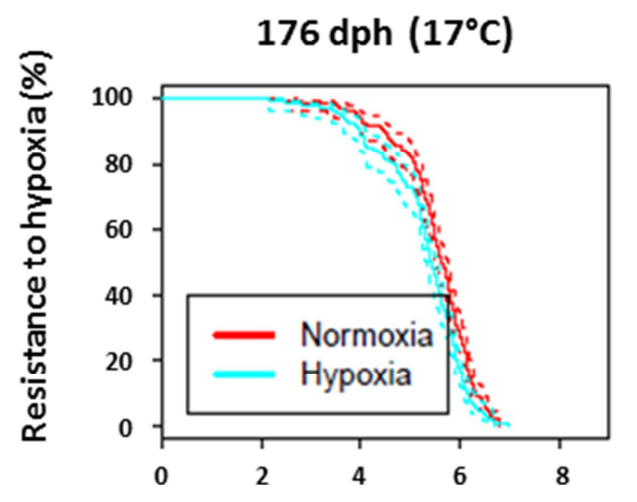

Time of exposure to hypoxia (hrs)

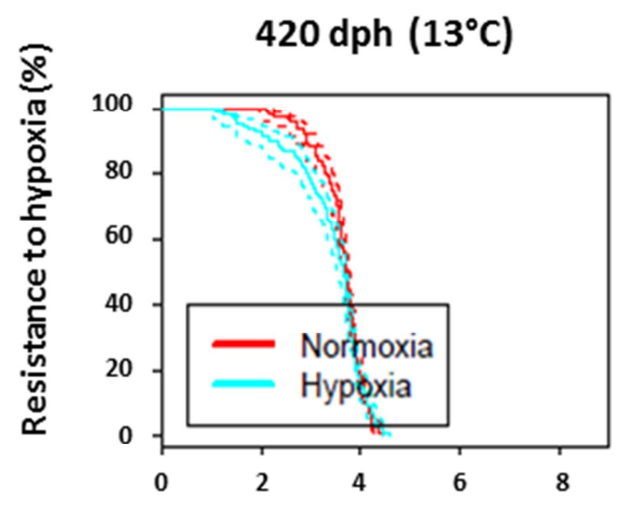

Time of exposure to hypoxia (hrs)

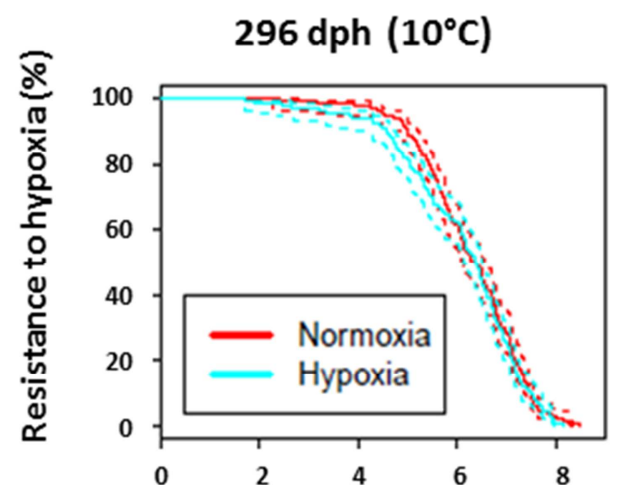

Time of exposure to hypoxia (hrs)

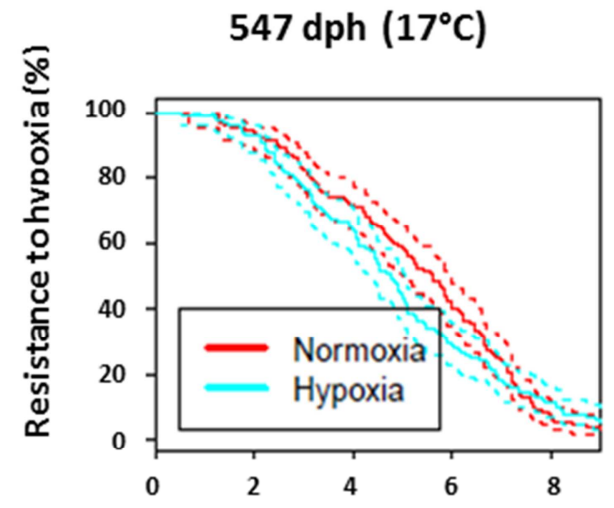

Time of exposure to hypoxia (hrs)

\begin{tabular}{cccc}
\hline & Chisq & Df & p-value \\
\hline Oxygen & 18.7 & 1 & $1.5^{*} 10^{-5}$ \\
\hline
\end{tabular}

Figure 2. Kaplan-Meier probability plot of tolerance time during a Hypoxia Challenge in juveniles early exposed during larval stage to normoxia (red lines) or hypoxia (blue lines). Continuous lines represent the percentage of individuals that resisted hypoxia up to the time point considered (also called the Kaplan-Meier estimator in survival analysis) and broken lines represent the associated $95 \%$ confidence intervals. The $\mathrm{Y}$ axis represents the percentage of individual that resisted hypoxia up to the time point considered. A total of four standardized hypoxia challenge tests were conducted over one year (at 176, 296, 420 and $547 \mathrm{dph}$ ). Juveniles tested for each group: normoxia (158) and hypoxia (165). Statistical differences of resistance time related to oxygen conditions were evaluated using Peto \& Peto (1972) modification of the log-rank test. Df : degrees of freedom; Chisq: Chisquared. 


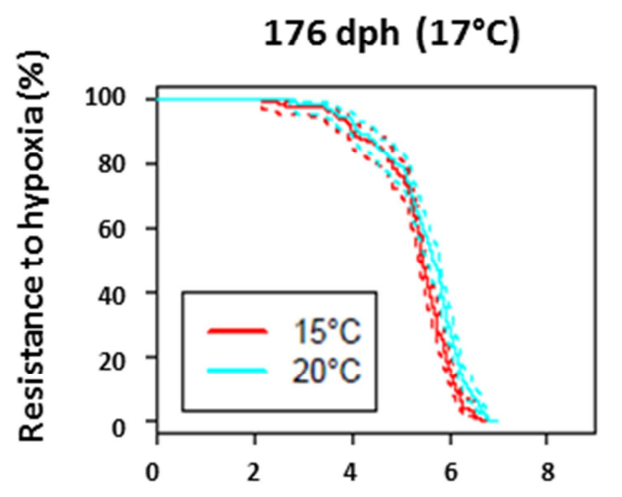

Time of exposure to hypoxia (hrs)

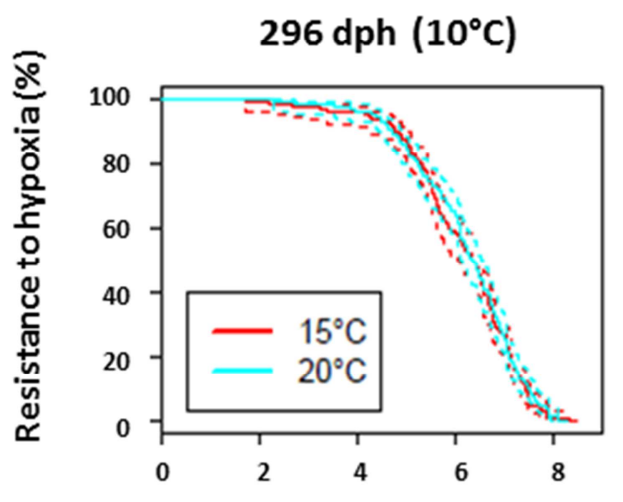

Time of exposure to hypoxia (hrs)

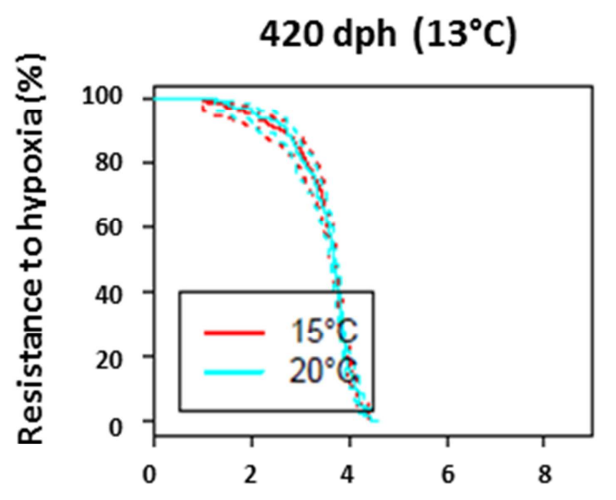

Time of exposure to hypoxia (hrs)

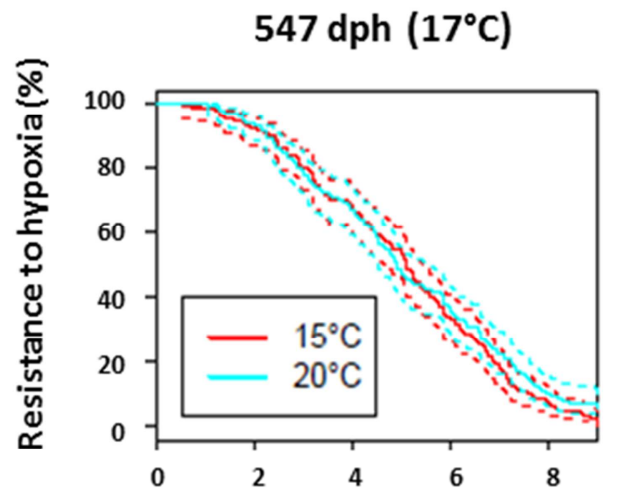

Time of exposure to hypoxia (hrs)

\begin{tabular}{lccc}
\hline & Chisq & Df & p-value \\
\hline Temperature & 7.5 & 1 & 0.07 \\
\hline
\end{tabular}

Figure 3. Kaplan-Meier probability plot of tolerance time during a Hypoxia Challenge in juveniles early exposed during larval stage to $15^{\circ} \mathrm{C}$ (red lines) or $20^{\circ} \mathrm{C}$ (blue lines). Continuous lines represent the percentage of individuals that resisted hypoxia up to the time point considered (also called the Kaplan-Meier estimator in survival analysis) and broken lines represent the associated $95 \%$ confidence intervals. The $Y$ axis represents the percentage of individual that resisted hypoxia up to the time point considered. A total of four standardized hypoxia challenge tests were conducted over one year (at 176, 296, 420 and $547 \mathrm{dph}$ ). Juveniles tested for each group: normoxia (158) and hypoxia (165). Statistical differences of resistance time related to temperature conditions were evaluated using Peto \& Peto (1972) modification of the log-rank test. Df : degrees of freedom; Chisq: Chi-squared. 


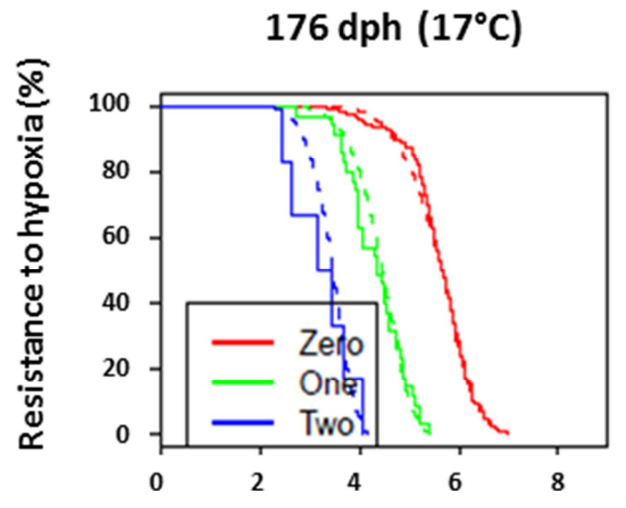

Time of exposure to hypoxia (hrs)

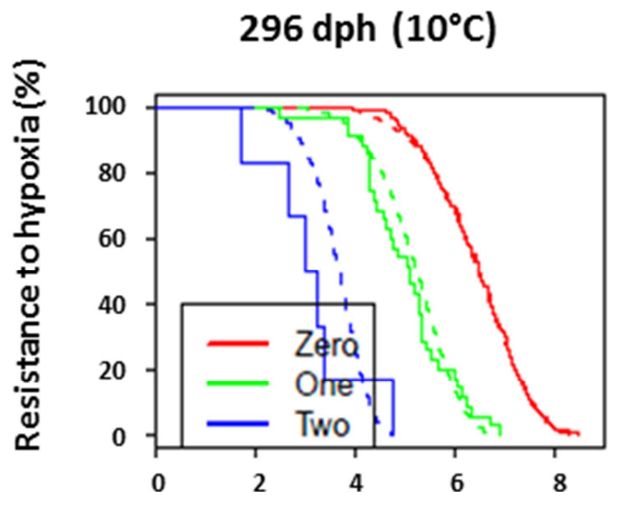

Time of exposure to hypoxia (hrs)

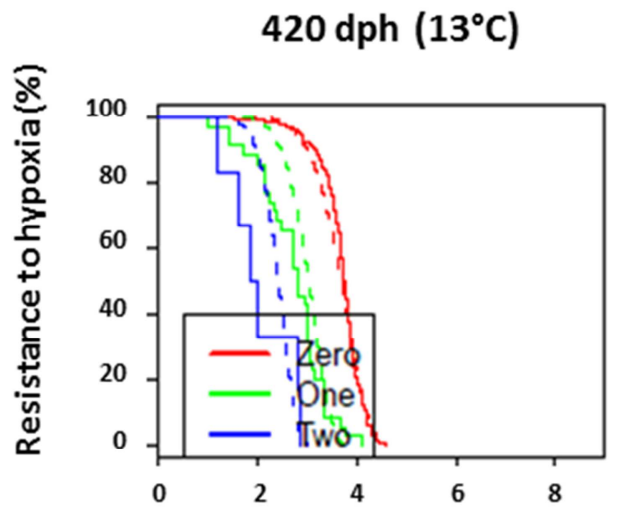

Time of exposure to hypoxia (hrs)

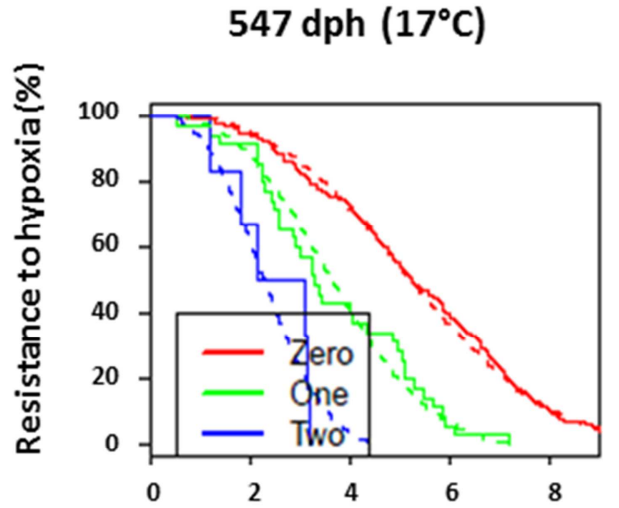

Time of exposure to hypoxia (hrs)

\begin{tabular}{llll}
\hline & Chisq & Df & p-value \\
\hline Strata (date) & 844 & 3 & $<1^{*} 10^{-4}$ \\
Opercular deformity & 244 & 2 & $<1^{*} 10^{-4}$ \\
Strata (date) ${ }^{*}$ Deformity & 657 & 6 & $<1^{*} 10^{-4}$ \\
\hline
\end{tabular}

Figure 4. Kaplan-Meier probability plot of tolerance time during a Hypoxia Challenge on the basis of the incidence of opercular deformities in sea bass juveniles: zero (red line), one-unilateral (green line) and two-bilateral (blue line). Continuous lines represent the percentage of individuals that resisted hypoxia up to the time point considered (also called the Kaplan-Meier estimator in survival analysis) and broken lines represent the associated $95 \%$ confidence intervals. The $Y$ axis represents the percentage of individual that resisted hypoxia up to the time point considered. A total of four standardized hypoxia challenge tests were conducted over one year (at 176, 296, 420 and $547 \mathrm{dph}$ ). $\mathrm{N}$ for each group: zero (282); one (35) and two (6). Statistical differences on the effect of date and opercular deformity on resistance time to hypoxia challenge test were evaluated using Weibull regression model. Df means degrees of freedom; Chisq: Chi-squared. 
- Sea bass juveniles exposed to moderate hypoxia at larval stage have lower tolerance to acute hypoxia

- Juveniles with opercular deformities exhibits lower resistance time to acute hypoxia

- Exposure to moderate hypoxia environment at larval stage induces opercular malformation 